freshly prepared metallic surface is now ready to be analyzed by XPS and/or AES.

Two other advantages are notable. Since the device is portable, it can be quickly adapted to similar spectrometers which may have different analysis capabilities (i.e., SIMS, LEED, etc.). In addition, because the scraper design pro- vides a reasonable approximation to metal extrusion processes, results can be applied toward the development of methods for fabricating reactive metals such as lithium.

Acknowledgment: We would like to thank R. Zengel for his design input and fabrication of the device.

\title{
The use of metallic glasses in fabrication of ICF targets ${ }^{\text {a) }}$
}

\author{
W. L. Johnson \\ Keck Laboratory of Engineering, California Institute of Technology, Pasadena, California 91125 \\ Mark C. Lee \\ Jet Propulsion Laboratory, Pasadena, California 91109 \\ (Received 17 November 1982; accepted 30 March 1983) \\ The fabrication of Au-base metallic glass spheres and microballoons used for ICF targets is \\ described. Alloys of composition $\mathrm{Au}_{55} \mathrm{~Pb}_{22.5} \mathrm{Sb}_{22.5}$ were used because of its low melting point and \\ high $\mathrm{Z}$ number. Metallic glass microspheres have a high degree of sphericity and surface \\ smoothness and deform homogeneously and isotropically under the high strain rates involved in \\ an ICF implosion.
}

PACS numbers: $81.20 . \mathrm{Gx}, 52.50 . \mathrm{Jm}$

The fabrication of ICF targets requires formation of spherical shells of high $Z$ metals with uniform wall thickness, sphericity, and surface roughness less than $0.1 \%$ of the wall thickness $(\sim 100 \AA \AA$ in specific cases). High strength, homogeneous, and isotropic materials are desirable for this purpose. Metallic glasses of high $\boldsymbol{Z}$ metals have been formed in spheres and microballoons by containerless processing methods ${ }^{1}$ and have been found to exhibit an exceptionally high degree of sphericity and surface smoothness. Under the high strain rates involved in an ICF implosion, metallic glasses are expected to deform homogeneously and isotropically. As such, these materials should be ideal for ICF target fabrication.

In the remainder of this paper, the results of a detailed study of Au-base metallic glass spheres and microballoons are outlined. In particular, alloys of composition $\mathrm{Au}_{55} \mathrm{~Pb}_{22.5} \mathrm{Sb}_{22.5}$ were chosen for this study. This choice of alloy materials was made for several reasons. First, the average $Z$ number of the constituent metals is $\langle z\rangle=73$, among the highest of any known glass forming systems. Second, the glass formation of $\mathrm{Au}_{x} \mathrm{~Pb}_{y} \mathrm{Sb}_{z}$ alloys has been studied in detail previously. ${ }^{2}$ It is thus known that under rapid cooling conditions, a large range of glass formation exists in this ternary system. Finally, the melting point of these alloys is rather low $\left(T_{m} \approx 260^{\circ} \mathrm{C}\right)$ so that the alloys can be conveniently handled in stainless steel or quartz crucibles with no siginficant contamination of the melt by reaction with the crucible material. The one undesirable feature of these materials is their rather low glass transiton temperature $T_{\mathrm{g}} \approx 60^{\circ} \mathrm{C}$. This low value of $T_{\mathrm{g}}$ results in considerable atomic mobility at ambient temperatures. As a consequence, the glasses are observed to partially crystallize when kept at ambient temperature for periods of several days or more and must be refrigerated if the glassy structure is to be maintained over longer periods.

Ingots of the $\mathrm{Au}_{55} \mathrm{~Pb}_{22.5} \mathrm{Sb}_{22.5}$ were prepared by melting high purity constituents in a sealed quartz ampule. These ingots were then used to fabricate spherules. ${ }^{1}$ The alloy was melted in a stainless steel vessel and forced through a fine orifice. For production of spherules in the $100-300 \mu \mathrm{m}$ range, a flow of inert gas was simultaneously passed through the opening in order to atomize the metal, while larger specimens were produced by the pendant drop method. The droplets were allowed to fall a distance of several meters. The spherules formed were then quenched into a liquid nitrogen bath at $-195^{\circ} \mathrm{C}$. Under these conditions, spherules of metallic glass were obtained with diameters ranging from $\sim 20$ $\mu \mathrm{m}$ up to $2 \mathrm{~mm}$. Figure 1(a) shows a SEM micrography of a glassy spherule with diameter $\sim 100 \mu \mathrm{m}$. Figure 1(b) shows the same sample with much higher magnification. For comparison Fig. 1(c) shows a spherule of crystallize alloy prepared under identical conditions but not quenched in the $\mathrm{LN}_{2}$ bath. The crystallized spherule has a far greater surface roughness. The glassy spherules were found to have surface 

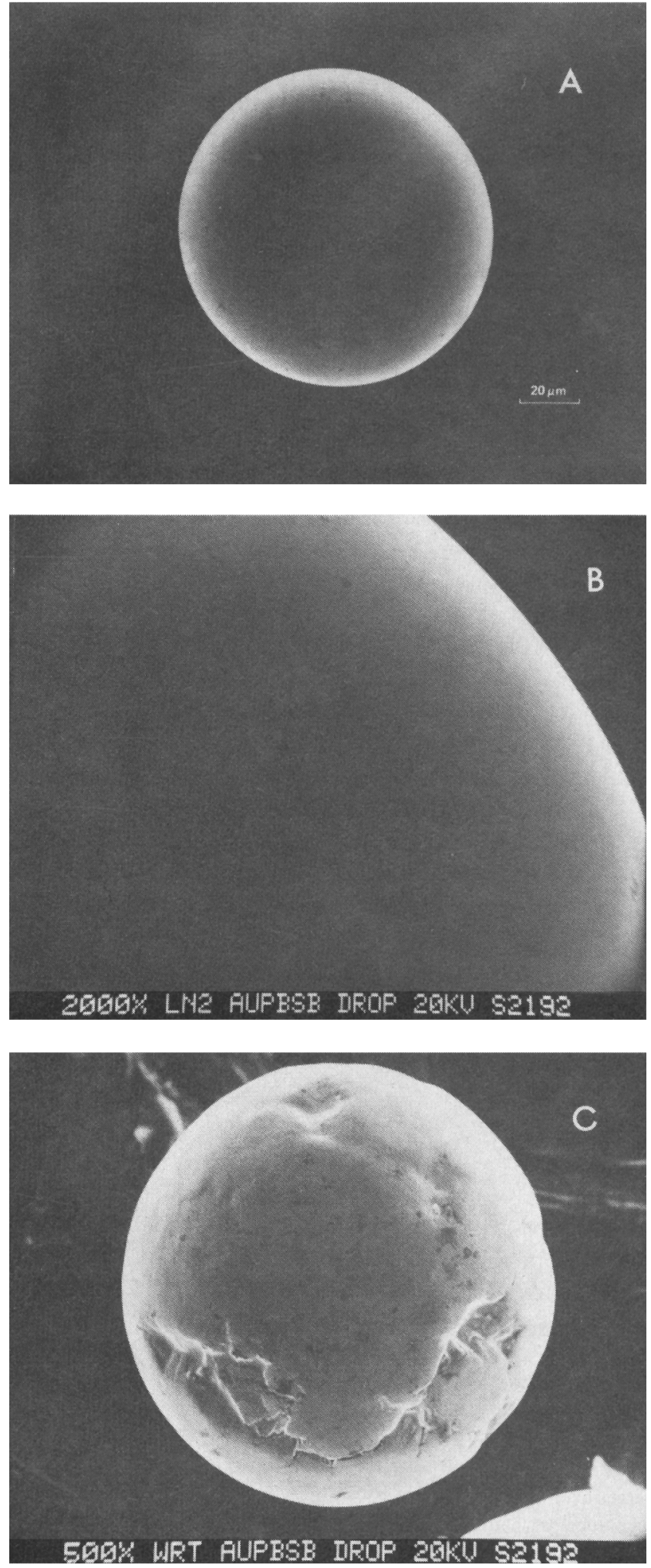

FIG. 1. SEM micrographs of (a) $\sim 100 \mu$ m spherule of $\mathrm{Au}-\mathrm{Pb}-\mathrm{Sb}$ metallic glass, (b) same sample at higher magnification, (c) crystallized spherule sample of $\mathrm{Au}-\mathrm{Pb}-\mathrm{Sb}$ alloy.

smoothness of order $10 \mathrm{~nm}$ and sphericity as good as $\sim 1 \%$. An x-ray diffraction pattern of a large number of $150-\mu \mathrm{m}$ spherules was obtained by step scanning with an $x$-ray diffractometer (Figure 2). The $x$-ray pattern is nearly identical to that obtained on rapidly quenched foils of the same material $^{2}$ and demonstrates that the spherules are indeed glassy.

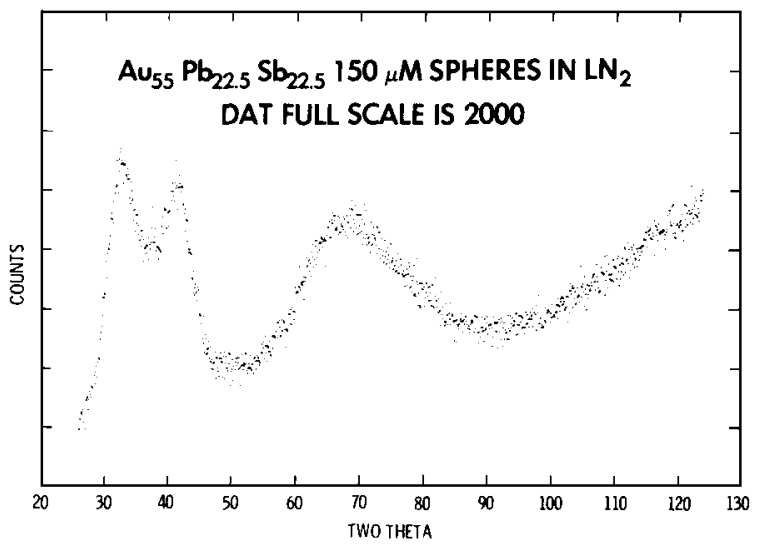

FIG. 2. X-ray diffraction pattern of a large number of $150 \mu \mathrm{m}$ spherules of $\mathrm{Au}-\mathrm{Pb}-\mathrm{Sb}$ metallic glass obtained with a scanning diffractometer using $\mathrm{Cu}$ $K \alpha$ radiation.

It is clear that the absence of crystallization results in a smooth and uniform spherule.

In a second phase of this work, it has been demonstrated that metallic glass microballoons (MGMB) of $\mathrm{Au}-\mathrm{Pb}-\mathrm{Sb}$ alloy can be formed using the hollow jet instability methods. ${ }^{3}$ We have synthesized microballoons ranging in size up to $2000 \mu \mathrm{m}$ with rather uniform wall thickness of $\sim 20 \mu \mathrm{m}$ (Figure 3).Thicknesses are determined by $x$-ray radiographs and SEM work on sliced section. Current efforts are focused on preparation of glassy metal shells having a varying range of diameter and wall thickness.

We believe that spherical microballoons of high $Z$, high density, metallic glasses such as $\mathrm{Au}-\mathrm{Pb}-\mathrm{Sb}$ should be an ideal substitute for the innermost concentric shells in ICF targets. Such shells are currently formed by coating heavy metals, polymers, and light metals on a hollow sphere of normal glass. In addition to the advantages already mentioned, it is believed that metallic glasses will deform homogeneously and isotropically under the exceedingly high strain rates involved in the collapse of a fusion target. Evidence for this comes from recent studies of dynamic compac-

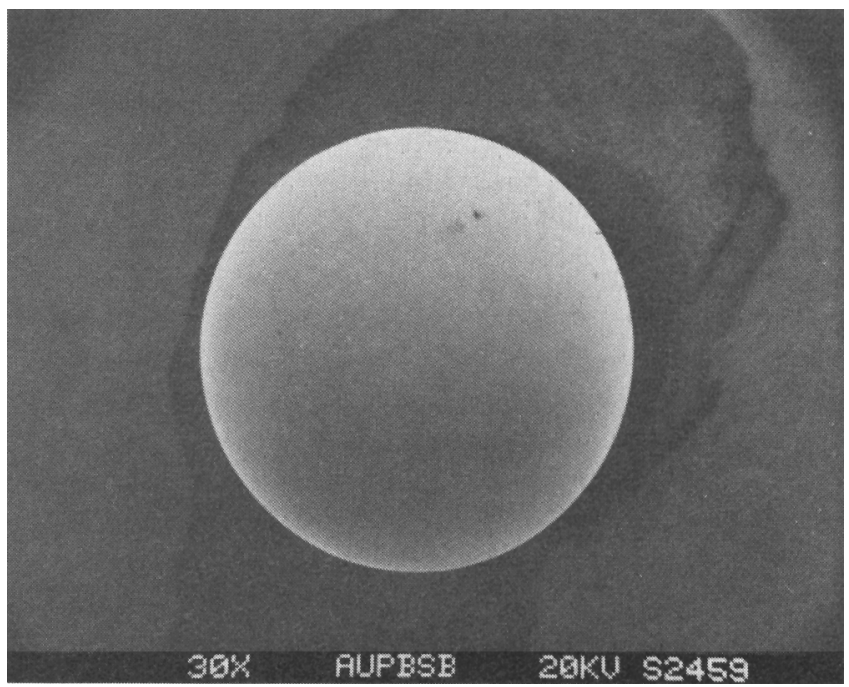

FIG. 3. Spherical shell of $\mathrm{Au}-\mathrm{Pb}-\mathrm{Sb}$ alloy formed using the hollow jet instability method as described in Ref. 3 . 
tion of metallic glass powders by explosively generated shock waves. ${ }^{4}$ For the high strain rates $\dot{\epsilon}>1\left(\mathrm{~s}^{-1}\right)$ attained on such studies, metallic glasses are observed to deform homogeneously. This is in contrast to the deformation behavior at low strain rates $\dot{\epsilon} \leqslant 1$ in which inhomogeneous deformation occurs by a shear instability in localized bands. ${ }^{5}$

\footnotetext{
a) This paper was presented at the 29th AVS National Symposium, and was partially supported by NASA.
}

${ }^{1}$ M. C. Lee, J. M. Kendall, and W. L. Johnson, Appl. Phys. Lett. 40, 382 (1982).

${ }^{2}$ C. O. Kim and W. L. Johnson, Phys. Rev. B 23, 143 (1981).

${ }^{3}$ M. C. Lee, J. M. Kendall, T. Wang, and W. L. Johnson, in Materials Processing in the Reduced Gravity Environment of Space, edited by G. E. Rindone (Elsevier, Boston, 1982), p. 105.

${ }^{4}$ C. F. Cline, J. Mahler, M. Finger, W. Kuhl, and R. Hopper, in Rapid Solidification Processing-Principles and Technologies, edited by R. Mehrabian, M. Cohen, and B. Kear (Claiturs, Baton Rouge, 1978), p. 380.

${ }^{5}$ L. A. Davis, in Metallic Glasses (American Society of Metals, Metals Park, Ohio 1978), p. 190.

\title{
Status report on ASTM E-42 Committee on surface analysis
}

\author{
P. H. Holloway ${ }^{a}$ \\ Department of Materials Science and Engineering, University of Florida, Gainesville, Florida 32611
}

(Received 16 July 1982; accepted 21 October 1982)

PACS numbers: 01.10.Hx, 82.80.Pv, 68.90. $+\mathrm{g}$

\section{INTRODUCTION}

Recognizing that surface analysis is rapidly becoming very important in a number of industrial installations and processes, a group of scientists within the American Society for Testing and Materials form (in 1974) a group which was aimed at producing standards and recommended practices for this field. Initially, this activity was conducted as a subcommittee of ASTM E-02 Committee on Emission Spectroscopy, but in 1976 the activity was transferred to a new committee within ASTM, E-42 Committee on Surface Analysis. The purpose of this committee is to advance the field of surface analysis (both in quality and breadth) through the development of appropriate standards, standard practices, reference data, reference materials, round robins, symposia, workshops, and publications. The committee currently has approximately 140 members and a wide sphere of influence through cooperating scientists and laboratories both within the United States and around the world. Progress reports on the committee's activity have been previously published, ${ }^{1-3}$ and activities within the committee have also been featured in the ASTM publication, "Standardization News."4

\section{E-42 SUBCOMMITTEE}

The primary activities of the committee are conducted by subcommittees which include: Auger electron spectroscopy; electron spectroscopy for chemical analysis (ESCA or XPS$\mathrm{x}$-ray photoelectron spectroscopy); ion scattering spectroscopy; secondary ion mass spectrometry; ion beam sputtering; standard reference materials; energetic ion analysis; terminology; and editorial. A list of the subcommittee chairmen and their addresses is given in Table $\mathrm{I}$, and persons interested in specific activities are encouraged to contact these persons. In addition, the current officers of Committee E-42 are listed in Table II. Additional information concern-

TABLE I. Subcommittee Officers of the E-42 Committee for 1982-1983.

Auger Subcommittee Chairman:

ISS Subcommittee Chairman:

SIMS Subcommittee Chairman

Ion Beam Sputtering

Subcommittee Chairman:

Standard Reference Materials Subcommittee Chairman:

Energetic Ion Analysis Subcommittee Chairman:

Terminology Subcommittee Chairman:

Editorial Subcommittee Chairman
J. T. Grant

University of Dayton Research Institute, College Park, Dayton, Ohio 45409

C. J. Wagner 29 Starview Drive, Oakland, California 94618

A. C. Miller

Alcoa Technical Center, Alcoa Center, Pennsylvania 15656

R. Colton

Naval Research

Laboratory,

Washington, DC 20375

A. J. Bevolo

Ames Laboratory,

Ames, Iowa 50011

J. Fine

National Bureau of Standards, Washington, DC 20234

J. Borders

Sandia National Laboratory, Albuquerque, New Mexico 87115

H. Tompkins Bell Laboratories, 6200 East Broad Street, Columbus, Ohio 43213

M. Urie

Westinghouse Hanford Co., Richland, WA 99352 